\title{
Movement of Tagged Juvenile Tailor (Pomatomus saltatrix) in Moreton Bay, Queensland
}

\author{
R. M. Morton ${ }^{\mathrm{A}}$, I. Halliday ${ }^{\mathrm{B}}$ and D. Cameron $^{\mathrm{B}}$ \\ ${ }^{A}$ WBM Oceanics Australia, PO Box 203, Brisbane, Qld 4004, Australia. \\ ${ }^{B}$ Southern Fisheries Centre, Queensland Department of Primary Industries, \\ PO Box 76, Deception Bay, Qld 4508, Australia.
}

\begin{abstract}
Large quantities of tailor, Pomatomus saltatrix, are caught by recreational and commercial fishers in coastal waters off New South Wales and Queensland. Juvenile tailor were subject to increasing fishing mortality in Moreton Bay (Queensland) in the mid 1980s. A tagging programme, involving State Government fisheries biologists and amateur fishing clubs, was established in 1986 to examine the movement, growth rate and fisheries exploitation of juvenile tailor $(<270 \mathrm{~mm}$ fork length) in Moreton Bay. Of 2173 juvenile tailor tagged in Moreton Bay during February-July and December 1987, 237 were recaptured over a period of 30 months, representing a recapture rate of $11 \%$. This was a high recapture rate compared with those in similar finfish tagging studies carried out in Moreton Bay. The recaptured fish moved relatively short distances (mean \pm s.d., $10 \cdot 2 \pm 15 \cdot 0 \mathrm{~km}$; maximum distance, $85 \mathrm{~km}$ ). Growth data were unreliable. Estuaries such as Moreton Bay function as nursery areas for tailor prior to their movement onto open surf beaches as adult fish. A legal minimum length for tailor was introduced on the basis of this study.
\end{abstract}

Extra keywords: tagging, estuarine fisheries, recreational fishing, fisheries exploitation.

\section{Introduction}

Tailor, Pomatomus saltatrix, occur in coastal subtropical and temperate waters of North and South America, southern Africa, and Australia. Along the eastern coast of Australia, they are commonly found between the latitudes of $24^{\circ} 30^{\prime} \mathrm{S}$ (the northern tip of Fraser Island, Queensland) and approximately $39^{\circ} \mathrm{S}$ (Wilson's Promontory, Victoria) (Bade 1977). Adult fish occur most commonly on open surf beaches and form large spawning aggregations from August to October (Pollock 1984). Pollock (1984) concluded that adult tailor migrate from southern coastal areas (including New South Wales) to Fraser Island to spawn during August-October, after which they disperse to the south. Tailor tagged at Fraser Island were recaptured southward at distances of up to $390 \mathrm{~km}$ (Pollock 1984). Eggs spawned at Fraser Island drift southwards under the influence of the East Australian Current (Hamon and Tranter 1971), and larval tailor presumably are dispersed along the coast and enter estuaries where conditions are favourable.

Large quantities of adult tailor are caught by commercial and recreational fishers in waters off northern New South Wales and southern Queensland, particularly during JuneNovember. The average annual commercial catch of adult tailor $(>300 \mathrm{~mm}$ total length, TL) in Queensland waters during 1988-90 was 209 t (Williams 1991). Juvenile tailor occur in estuarine areas and are often taken by anglers. Juvenile tailor were subject to increased fishing pressure in Queensland waters during the mid 1980s, primarily as a result of an increasing number of anglers and recreational motor boats. A legal minimum length for 
tailor did not exist prior to 1987 (the year of the present study). Concern was expressed to the Queensland Department of Primary Industries (QDPI) by anglers about recent declines in tailor catch rates and about the capture in Moreton Bay of large numbers of juvenile tailor by commercial net fishers.

Williams (1991) reported that an annual mean catch of $83 \mathrm{t}$ of tailor was taken by commercial net fishers from the Moreton Bay region in 1988-90. Although no data are available for Moreton Bay specifically, most (approximately $70 \mathrm{t}$ ) of this catch would have been adult tailor taken from the ocean beaches of Moreton and North Stradbroke Islands, outside Moreton Bay, whereas landings within Moreton Bay probably total $15 \mathrm{t}$ annually (Williams, personal communication). Commercial net fishers in Moreton Bay target tailor, although many are taken as a by-catch. Tailor taken by set-net fisheries are generally adolescents and adults (owing to net mesh sizes), and juveniles are occasionally taken by river beam trawlers.

Anglers in Moreton Bay commonly capture adolescent and juvenile tailor throughout the year, in contrast to anglers on the ocean beaches who target adult fish in winter and spring. Neumann and Hundloe (1986) reported that tailor occur in $21 \cdot 3 \%$ of angler catches in Moreton Bay. Although no data for Moreton Bay are available, angler landings in the bay are probably less than those at ocean beaches adjacent to the bay and are certainly less than landings in areas such as Fraser Island, where annual angler landings (180 t) substantially exceed commercial landings (25-55 t) (Pollock 1980).

Very little information is available on juvenile and adolescent tailor in Australia. Bade (1977) concluded that in southern Queensland waters most male tailor were sexually mature at $260 \mathrm{~mm}$ fork length (FL), whereas most females were sexually mature at $280 \mathrm{~mm}$ FL. Adult tailor migrations and subsequent spawning aggregations, usually in late winter and early spring, are well documented for many countries, including North America's eastern coast (Wilks 1977; Kendall and Walford 1979), South Africa's south-eastern coast (Van der Elst 1976; Joubert 1981), and Australia's eastern coast (Pepperell 1980; Pollock 1984). Van der Elst (1976) noted that in South Africa juvenile tailor enter estuaries at lengths of about $40-50 \mathrm{~mm}$ fork length (FL) and attain a length of approximately $230 \mathrm{~mm}$ FL after their first year.

The present study was initiated in view of the lack of information available on juvenile tailor and the reportedly increasing number of fishers targeting tailor. It aimed to examine the movement and growth rate of juvenile tailor stocks within Moreton Bay, Queensland.

\section{Materials and Methods}

A joint tagging programme was developed between the QDPI and fishing clubs (recreational and sportfishing) whereby volunteer club anglers were provided with transport, bait and tackle by the QDPI to capture juvenile tailor for tagging.

Tailor were tagged and released at three sites in Moreton Bay, south-eastern Queensland (Fig. 1): Skirmish Point (Bribie Island), a semi-protected surf beach adjacent to open surf beaches at the northern end of Moreton Bay; Jumpinpin, a surf bar at the mouth of an estuary in southern Moreton Bay; and the Houghton Highway Bridge at the mouth of a large river estuary, the Pine River, in central Moreton Bay. These sites were selected because they are known to be regions where juvenile tailor congregate and are consequently heavily fished by anglers.

Tagging was carried out by QDPI officers from February to July and during December of 1987. All tailor were captured by volunteer anglers from southern Queensland fishing clubs, angling from both boats and beaches. Tailor were captured with rigs consisting of three linked ('ganged') No. 2 Mustad hooks baited with white pilchards (Engraulis australis). Lures were used to capture a small number of fish (67). When a fish was caught, the hooks were carefully removed by QDPI officers. Prior to tagging, the FL of each fish was measured to the nearest $5 \mathrm{~mm}$. Anchor (T-bar) tags (45 mm long and $0.5 \mathrm{~mm}$ in diameter) were inserted into the dorsal musculature below the first dorsal fin. Each tag was uniquely numbered and carried a toll-free telephone number and the letters 'QDPI'. Fish that were 'gut-hooked' or that sustained gill damage were not tagged. 


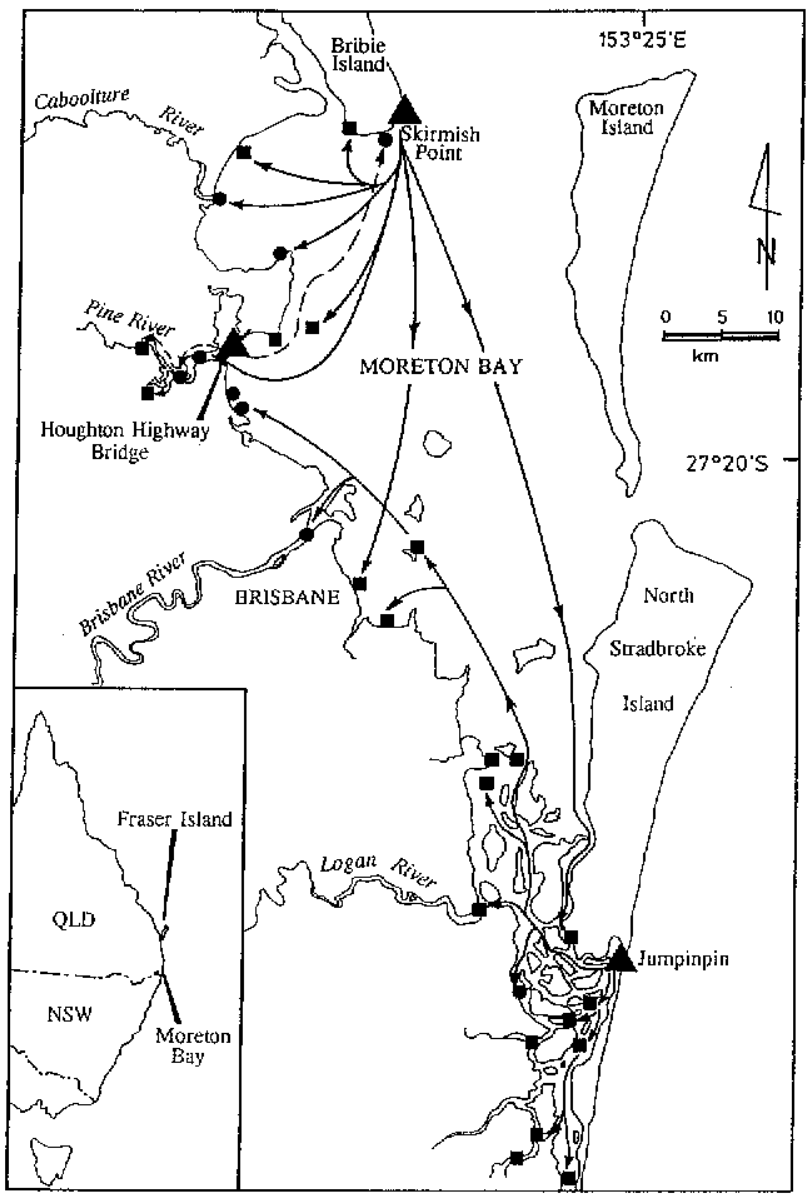

Fig. 1. Map of Moreton Bay, Queensland, showing sites where juvenile tailor were tagged (A) and recaptured (more than $2 \mathrm{~km}$ from tagging sites: $\square,<5$ fish; - $>5$ fish).

The tagging programme was advertised in the regular fishing columns of Brisbane newspapers and by promotional material distributed to tackle shops in south-eastern Queensland. Persons recapturing tagged fish were asked to retain the fish (or its frame) intact. Only those recaptured tagged fish returned to and measured by QDPI officers were used for growth estimates.

Only tailor measuring $\leqslant 270 \mathrm{~mm} F L$, classified as juveniles for the purpose of this study (see Bade 1977), were tagged. Distances between release and recapture sites were measured by the most direct water route.

\section{Results}

Of 2173 juvenile tailor tagged and released, $237(11 \%)$ were recaptured within Moreton Bay over a period of 30 months. Table 1 shows the number of fish tagged and released at each site, the average length of fish released, and the number of fish recaptured.

Tag recoveries indicated that juvenile tailor tagged at Jumpinpin and Skirmish Point moved over most areas of Moreton Bay. Fish tagged at Skirmish Point were recaptured at the Caboolture, Pine and Brisbane Rivers and Jumpinpin (Fig. 1). Similarly, fish tagged at Jumpinpin were recaptured at the Logan and Brisbane Rivers and the Houghton Highway Bridge.

Juvenile tailor at Houghton Highway Bridge were smaller than those tagged at the other sites (Table 1); they were recaptured within the Pine River estuary or, in a solitary case, at Skirmish Point. 
Table 1. Release and recapture data for juvenile tailor tagged in Moreton Bay All lengths are fork length $(\mathrm{mm})$. Numbers in parentheses: $n$, number of fish returned for growth estimates; s.d., standard deviation of mean growth rate

\begin{tabular}{lcccccc}
\hline \multicolumn{1}{c}{ Release site } & $\begin{array}{c}\text { Number } \\
\text { tagged }\end{array}$ & $\begin{array}{c}\text { Number } \\
\text { returned }\end{array}$ & $\begin{array}{c}\text { Percentage } \\
\text { returned }\end{array}$ & $\begin{array}{c}\text { Mean } \\
\text { release } \\
\text { length }\end{array}$ & $\begin{array}{c}\text { Mean } \\
\text { recapture } \\
\text { length }(n)\end{array}$ & $\begin{array}{c}\text { Mean growth, } \\
\text { mm day }^{-1} \\
( \pm \text { s.d. })\end{array}$ \\
\hline Skirmish Point & 974 & 107 & $11 \cdot 0$ & $197 \cdot 1$ & $210 \cdot 1(66)$ & $0 \cdot 20( \pm 0 \cdot 50)$ \\
Jumpinpin & 732 & 65 & $8 \cdot 9$ & $206 \cdot 1$ & $209 \cdot 1(24)$ & $0 \cdot 24( \pm 0 \cdot 18)$ \\
Houghton Highway Bridge & 467 & 65 & $13 \cdot 9$ & $183 \cdot 2$ & $205 \cdot 1(38)$ & $0 \cdot 12( \pm 0 \cdot 09)$ \\
& & & & & & \\
Total & 2173 & 237 & $10 \cdot 9$ & $197 \cdot 2$ & $208 \cdot 5(128)$ & $0 \cdot 18( \pm 0 \cdot 37)$ \\
\hline
\end{tabular}

Although $9 \%$ of recaptured fish were taken within 14 days of release, $64 \%$ were at liberty for more than 40 days (mean \pm s.d., $74 \cdot 8 \pm 80 \cdot 4$ days; Table 2 ). The shortest period of liberty was $1 \mathrm{~h}$. The longest was 899 days; this fish was tagged at Jumpinpin and recaptured in the Logan River (15 $\mathrm{km}$ distant by water).

Table 2. Mean and maximum days of liberty, mean distances between release and recapture sites, percentages of recaptured fish returned by amateur fishers, and percentages of fishers targeting juvenile tailor in Moreton Bay

\begin{tabular}{llcccc}
\hline Release site & \multicolumn{2}{c}{$\begin{array}{c}\text { Days of liberty } \\
\text { Mean } \\
( \pm \text { s.d. })\end{array}$} & $\begin{array}{c}\text { Movement } \\
(\mathrm{km}), \\
\text { mean }( \pm \text { s.d. })\end{array}$ & $\begin{array}{c}\text { Percentage recapture } \\
\text { Amateur }\end{array}$ & $\begin{array}{c}\text { Targeting } \\
\text { tailor }\end{array}$ \\
\hline Skirmish Point & $68 \cdot 1( \pm 68 \cdot 3)$ & 560 & $12 \cdot 9( \pm 15 \cdot 8)$ & 100 & $57 \cdot 9$ \\
Jumpinpin & $65 \cdot 0( \pm 112 \cdot 5)$ & 899 & $13 \cdot 3( \pm 18 \cdot 0)$ & $98 \cdot 5$ & $47 \cdot 1$ \\
Houghton Highway Bridge & $95 \cdot 5( \pm 53 \cdot 6)$ & 240 & $2 \cdot 6( \pm 3 \cdot 8)$ & $89 \cdot 2$ & $35 \cdot 4$ \\
Total & $74 \cdot 8( \pm 80 \cdot 4)$ & $10 \cdot 2( \pm 15 \cdot 0)$ & $96 \cdot 6$ & $50 \cdot 6$ \\
\hline
\end{tabular}

The distances between release and recapture sites were relatively short (mean \pm s.d., $10 \cdot 2 \pm$ $15.0 \mathrm{~km}$; Table 2; maximum distance, $85 \mathrm{~km}$ ), and all recaptured fish were caught within Moreton Bay (Fig. 1). Minimum movement rates were generally less than $0.33 \mathrm{~km}$ day $^{-1}$, although some fish moved relatively quickly $\left(3 \cdot 5\right.$ to $10 \mathrm{~km}$ day $\left.{ }^{-1}\right)$. The fastest movement recorded was for a fish (205 mm FL) tagged at Jumpinpin and recaptured $13 \mathrm{~h}$ later at $8 \mathrm{~km}$ from the tagging site.

Most tagged fish $(97 \%$ ) were taken by anglers (Table 2). Commercial fishers caught tagged tailor in beam trawls, and one tagged fish was taken by gill-net.

Only $54 \%$ (128) of recaptured tailor were returned to the QDPI for measuring. Growth rates of juvenile tagged tailor (Table 1 ) were found to be highly variable (mean \pm s.d., $0 \cdot 18 \pm 0.37 \mathrm{~mm}$ day $^{-1}$ ). Fish were recaptured throughout the year, but too few were returned within a particular season to provide a statistically valid analysis of fish growth. Three fish at liberty for longer than 90 days did not grow at all, whereas 13 others released at the same time of the year and at liberty for more than 90 days had growth rates of $0.20 \mathrm{~mm} \mathrm{day}{ }^{-1}$ or greater. Six of the recaptured fish were found to be smaller than when tagged (maximum difference observed, $15 \mathrm{~mm}$ ) after periods greater than one month after release. These were not included in growth rate estimates. 


\section{Discussion}

The tailor fishery in Queensland is large and important to both commercial fishers and anglers. The recapture rate $(11 \%)$ and the short periods of liberty of many fish in the present study indicate moderately high fishing pressure, principally by anglers, on juvenile tailor populations within Moreton Bay in comparison with other angling fisheries in the region (Bade 1977, 7.6\% recapture rate; Pollock 1982, 5.9\%; Pollock 1984, 5.9\%; Morton $1985,5 \cdot 5 \%$ ). Alternatively, tagged fish may have remained at the tagging sites, which are reputed by anglers to be areas where juvenile tailor congregate, and hence were particularly susceptible to recapture, resulting in a high percentage of returns.

The high recapture rate for fish tagged at the Houghton Highway Bridge (14\%), compared with the other release sites, indicates that anglers catch substantial quantities of juvenile tailor from this area. Some anglers interviewed during the tagging study reported taking up to 100 juvenile tailor in a single trip. Many of these fish were considered by anglers to be too small for human consumption and were reportedly being used as pet food. Juvenile tailor, captured commercially, were also being marketed at sizes from $200 \mathrm{~mm}$ FL in early stages of the present study.

The higher recapture rate at the Houghton Highway Bridge may also have resulted from greater fishing effort at that release site than at other sites. Unfortunately, no data are available on relative fishing effort in various parts of Moreton Bay. However, general impressions suggest that angler effort is similar at the easily accessible areas of Skirmish Point and Houghton Highway Bridge but lower at Jumpinpin, access to which requires a four-wheel-drive vehicle or a motor boat. Differences in recapture rates could have resulted from changes in recapture vulnerability at release sites. Fish tagged at Jumpinpin and Skirmish Point were more mobile (Table 2) and may have emigrated from Moreton Bay, perhaps reducing their vulnerability to recapture.

Sheltered estuaries such as the Pine River estuary appear to function as tailor nursery areas. Almost all fish captured for tagging in the Pine River (Houghton Highway Bridge) were small compared with those captured in more oceanic estuarine areas such as Jumpinpin or Skirmish Point, and they moved shorter distances, remaining close to the Pine River estuary. Such protected estuarine areas provide abundant food and shelter (Stephenson and Dredge 1976; Blaber and Blaber 1980; Morton 1990) for juvenile tailor. Other relatively undisturbed estuaries within Moreton Bay probably perform a similar function. Juvenile tailor remain in sheltered estuaries (such as the Pine River) while they are small and move into more open bay areas when they become larger. Tailor in more exposed areas of Moreton Bay (such as Skirmish Point and Jumpinpin) move over a wider range of habitats (estuaries, open bays, surf bars). These fish mature and eventually leave the bay areas for open surf beaches. Anglers commonly report taking tailor $250-300 \mathrm{~mm}$ FL on surf beaches. Pollock (1984) reported a size range of $250-560 \mathrm{~mm}$ FL for tailor at Fraser Island.

Estimates of length increments from release-recapture data were highly variable and could not be used for estimating tailor growth rates. Tagging caused obvious wounds that failed to heal during the period of liberty. This may have adversely affected fish growth rates and might explain the wide variations in the few growth estimates obtained. Tagging wounds may also have resulted in increased fish mortality. Several returned tags were abraded and it is probable that some fish lost their tags. Tag loss and emigration of tailor from Moreton Bay (as juvenile fish matured) would have reduced the number of tagged fish available for recapture in Moreton Bay, resulting in tailor exploitation rates being underestimated. Most reported recaptures $(96 \%)$ occurred within six months of the release of tagged fish.

The present study demonstrates the benefits of a cooperative tagging project involving a government regulatory body and amateur fishing clubs. Large numbers of juvenile tailor were tagged, and the results indicated a high exploitation rate by anglers. The taking of large numbers of juvenile tailor was considered likely to be a contributing factor to reported 
decreases in catch rates of adult tailor, and a legal minimum length was introduced in 1987 following analysis of data collected from the tailor tagged and released during FebruaryJuly (1987). This prohibited the retention of more than six tailor smaller than $300 \mathrm{~mm}$ total length by anglers and prohibited the taking of all tailor smaller than this length by commercial fishers. The legislation has since been reviewed, and since 1990 it has been illegal for anglers to retain any fish smaller than this. The publicity associated with the programme and the involvement of amateurs has raised awareness of the benefits of a legal minimum length.

\section{Acknowledgments}

This study was funded by the Queensland Department of Primary Industries. Departmental officers, particularly Dawn Couchman, Karen Greenwood, Peter Stephens and Brad Zeller, provided valuable assistance that is gratefully acknowledged. We thank the many amateur anglers who helped to catch fish for tagging and reported recaptured fish. Messrs D. Bateman, B. Pollock and S. Watson were especially important in capturing tailor, and their angling expertise provided many of the fish for tagging.

\section{References}

Bade, T. M. (1977). The biology of tailor (Pomatomus saltatrix Linn.) from the east of Australia. M.Sc. Thesis, University of Queensland, St Lucia.

Blaber, S. J. M., and Blaber, T. G. (1980). Factors affecting the distribution of juvenile estuarine and inshore fishes. Journal of Fish Biology 17, 143-62.

Hamon, B. V., and Tranter, D. J. (1971). The East Australian Current. Australian Natural History $17,129-33$.

Joubert, C. S. W. (1981). A survey of shore anglers' catches at selected sites on the Natal coast, South Africa. Oceanographic Research Institute (Durban) Investigational Report No. $52.15 \mathrm{pp}$.

Kendall, A. W., and Walford, L. A. (1979). Sources and distribution of bluefish, Pomatomus saltatrix, larvae and juveniles off the east coast of the United States. Fishery Bulletin (US) 77, 213-27.

Morton, R. M. (1985). The tagging of summer whiting, Sillago cililata C. and V., in northern Moreton Bay, Queensland. Australian Zoologist 21, 491-502.

Morton, R. M. (1990). Community structure, density and standing-crop of fishes in a subtropical Australian mangrove area. Marine Biology (Berlin) 105, 384-94.

Neumann, R., and Hundloe, T. (1986). The characteristics of recreational fishing in the Moreton region. Griffith University, Institute of Applied Environmental Research, Environmental Information Series Research Report No. 1.

Pepperell, J. (1980). Tailor: answering some questions. In 'Fish and Fisheries No. 1'. (Ed. T, Law.) pp. 48-51. (New South Wales Government Printer: Sydney.)

Pollock, B. R. (1980). Surprises in Queensland angling study. Australian Fisheries 39(4), 17-19.

Pollock, B. R. (1982). Movement and migration of yellowfin bream, Acanthopagrus australis (Günther), in Moreton Bay, Queensland, as determined by tag recoveries. Journal of Fish Biology 20, 245-52.

Pollock, B. R. (1984). The tailor fishery at Fraser Island and its relation to the life-history of the fish. Proceedings of the Royal Society of Queensland 95, 23 8 .

Stephenson, W., and Dredge, M. C. L. (1976). Numerical analysis of fish catches from Serpentine Creek. Proceedings of the Royal Society of Queensland 87, 33-43.

Van der Elst, R. (1976). Game fish of the east coast of southern Africa. I. The biology of elf, Pomatomus saltatrix (Linnaeus), in the coastal waters of Natal. Oceanographic Research Institute (Durban) Investigational Report No. 44.

Wilks, S. J. (1977). Biological and fisheries data on bluefish, Pomatomus saltatrix (Linnaeus). US National Oceanic and Atmospheric Administration, Northeast Fisheries Center, Sandy Hook Laboratory, Technical Series Report No. 11.

Williams, L. C. (1991). Ocean beach fishery catch. In 'Directions for Change: Proceedings of the Ocean Beach Fishing Seminar, Brisbane, 19-20 September 1991'. (Ed. A. Magee.) pp. 12-15. (Queensland Fish Management Authority: Brisbane.) 